\title{
Estimating dominant runoff modes across the conterminous United States
}

\author{
Brian Buchanan $^{1}$ (1) | Daniel A. Auerbach ${ }^{2}$ (D) | James Knighton ${ }^{6}$ | Darrick Evensen ${ }^{3}$ | \\ Daniel R. Fuka ${ }^{4}$ | Zachary Easton ${ }^{4}$ | Michael Wieczorek ${ }^{5}$ | Josephine A. Archibald ${ }^{1}$ | \\ Brandon McWilliams ${ }^{1}$ । Todd Walter ${ }^{6}$
}

${ }^{1}$ Department of Civil and Environmental Engineering, Seattle University, Seattle, Washington, USA

${ }^{2}$ Fish Program, Washington Department of Fish and Wildlife, Olympia WA 98501, USA

${ }^{3}$ University of Edinburgh, Politics and International Relations Department, 22 George Square, Room B.2, Edinburgh EH8 9LF, Scotland, UK

${ }^{4}$ Department of Biological Systems Engineering, Virginia Tech, Blacksburg, Virginia, USA

${ }^{5}$ MD-DE-DC Water Science Center, United States Geological Survey, Baltimore, Maryland, USA

${ }^{6}$ Department of Biological and Environmental Engineering, Cornell University, Ithaca, New York, USA

\section{Correspondence}

Brian Buchanan, Department of Civil and Environmental Engineering, Seattle University, Seattle, WA 98122.

Email: bb386@cornell.edu

\begin{abstract}
Effective natural resource planning depends on understanding the prevalence of runoff generating processes. Within a specific area of interest, this demands reproducible, straightforward information that can complement available local data and can orient and guide stakeholders with diverse training and backgrounds. To address this demand within the contiguous United States (CONUS), we characterized and mapped the predominance of two primary runoff generating processes: infiltration-excess and saturation-excess runoff (IE vs. SE, respectively). Specifically, we constructed a gap-filled grid of surficial saturated hydraulic conductivity using the Soil Survey Geographic and State Soil Geographic soils databases. We then compared surficial saturated hydraulic conductivity values with 1 -hr rainfall-frequency estimates across a range of return intervals derived from CONUS-scale random forest models. This assessment of the prevalence of IE versus SE runoff also incorporated a simple uncertainty analysis, as well as a case study of how the approach could be used to evaluate future alterations in runoff processes resulting from climate change. We found a low likelihood of IE runoff on undisturbed soils over much of CONUS for 1-hr storms with return intervals $<5$ years. Conversely, IE runoff is most likely in the Central United States (i.e., Texas, Louisiana, Kansas, Missouri, lowa, Nebraska, and Western South Dakota), and the relative predominance of runoff types is highly sensitive to the accuracy of the estimated soil properties. Leveraging publicly available data sets and reproducible workflows, our approach offers greater understanding of predominant runoff generating processes over a continental extent and expands the technical resources available to environmental planners, regulators, and modellers.
\end{abstract}

\section{KEYWORDS}

contiguous United States, infiltration excess runoff, precipitation frequency analysis, random forest, runoff generation, saturation excess runoff

\section{1 | INTRODUCTION}

Answering the question "how does water move here?" is fundamental to diverse management objectives, such as regulatory compliance, agricultural production, and biodiversity conservation. Characterizing 
example, in places with soils having high clay content, compaction, or impervious surfaces. Conversely, saturation-excess runoff (hereafter referred to as SE) is more likely in regions where infiltration capacity exceeds precipitation, for example, in places which have humid, well-vegetated, and low-lying areas where surface and subsurface flows converge.

Characterizing the prevalent runoff process is fundamental to sound decision support of management objectives; a mischaracterization of which may lead to invalid decisions or models that are wrong or "right for the wrong reasons" due to myriad degrees of model freedom that obscure process uncertainty (Kirchner, 2006). At the watershed scale, various studies have firmly established that assumptions regarding the balance of Hortonian and variable source area (VSA) processes fundamentally affect the accuracy and utility of predictions (e.g., Beven \& Binley, 1992; Beven \& Kirkby, 1979) and directly inform the data used to support field-scale implementation of best management practices (Easton, Walter, Zion, Schneiderman \& Steenhuis, 2009; Walter et al., 2003). For instance, where and when SE dominates, a topographic wetness index can effectively depict finescale spatial moisture patterns by revealing variable runoff source areas with lower gradients and greater contributing areas (Buchanan et al., 2014; Easton et al., 2008).

Landscape-scale hydrologic models developed for use at coarse spatial and temporal scales would similarly benefit from a better understanding of the dominant runoff modes across the contiguous United States (CONUS). For example, meso-scale Land Surface Models (LSMs) average over true horizontal heterogeneity of the catchment at resolutions optimized for the atmospheric flow computations within general circulation models, commonly to 0.5 degrees horizontal resolution (Beven, Cloke, Pappenberger, Lamb, \& Hunter, 2015; Mendoza et al., 2015). Oversimplification of hydrologic heterogeneity due to spatial averaging can lead to issues in prediction of the catchment energy balance and evapotranspiration (Freund, Fan, \& Kirchner, 2017; Shrestha, Sulis, Simmer, \& Kollet, 2018), stored catchment water (Shrestha, Sulis, Simmer, \& Kollet, 2015), and surface runoff (Nijzink \& Savenije, 2016; Tesfa et al., 2014).

Additionally, LSMs typically represent surface runoff exclusively as an infiltration-excess process or consider IE or SE processes across the spatial domain of interest to be mutually exclusive, despite recent research suggesting substantial runoff process heterogeneity within the CONUS (Segura, Caldwell, Sun, McNulty, \& Zhang, 2014; Wolock, 2003). A spatial description of the dominant runoff modes across the CONUS would provide hydrologists a reasonable framework for understanding which surface runoff generation scheme is most appropriate and where averaging over true spatial heterogeneity may be problematic for prediction of surface discharge.

Effective modelling, program planning and implementation depends, therefore, on knowing the prevalence of these processes. This demands information that is straightforward-to orient and guide stakeholders with diverse training and backgrounds-and reproducibly derived as a complement to local knowledge. Past studies suggest that an index relating characteristic precipitation to soil hydraulic conductivity at landscape scales may meet these criteria. For example, Walter et al. (2003) examined seasonal rainfall frequencies at a single weather station in relation to U.S. Natural Resource Conservation Service soil survey geographic data (NRCS SSURGO) for watersheds draining to New York City water supply reservoirs. Congruent with other research in the area, they found clear evidence of primarily VSA processes. In turn, these results strongly informed the data and modelling tools deployed in programs to mitigate contamination from manure application or to reduce overland sediment inputs. In related work at a larger spatial extent, Wolock (2003) performed comparable frequency analyses of records from weather stations throughout the United States. This then formed the basis of synthetic climate inputs to a modified version of TOPMODEL that was used to produce gridded estimates of the percentage of Hortonian overland runoff in total streamflow (5 km grid cells for conterminous United States, CONUS). Incorporating these estimates into the Geospatial Attributes of Gages for Evaluating Streamflow (GAGESII) data set of catchment attributes for United States Geological Survey (USGS) streamflow gages (Falcone et al., 2010) has supported subsequent inquiries. For example, continental scale studies found these "percentage Hortonian" values to be important predictors of stream temperatures in low to moderate elevation catchments (Segura et al., 2014) and of annual runoff ratios in basins with minimal water infrastructure (Chang, Johnson, Hinkley, \& Jung, 2014). Likewise, watershed-scale studies demonstrated that percent Hortonian values were strong predictors of ecologically relevant streamflow characteristics in the Tennessee and Cumberland River basins (Knight, Gain, \& Wolfe, 2011).

Building on such research and seeking to improve the technical resources readily available to planners, regulators, and modellers, we conducted a study in three phases. First, we built $90 \mathrm{~m}$ area-weighted grids of saturated hydraulic conductivity $\left(\mathrm{K}_{\mathrm{SAT}}\right)$ for the surface soil horizon across CONUS. Second, we used conditional inference random forest (CIRF) models to predict 1-hr storm magnitudes for a variety of return intervals over CONUS. Third, we determined the prevalence of IE versus SE runoff by comparing 1-hr storm depths across the various return intervals to a range of $\mathrm{K}_{\mathrm{SAT}}$ values. Our approach leverages publicly available data sets and offers a reproducible workflow as new data become available.

\section{2 | METHODS}

\section{1 | Soils data}

Precipitation depths associated with various storm return intervals were compared with "K $\mathrm{SAT}$ " values derived from the Natural Resource Conservation Service soil survey data (Soil Survey Staff, 2017b). Specifically, we created a 90-m grid of area-weighted representative $\mathrm{K}_{\mathrm{SAT}}$ values of the surface horizon for all soil components in each mapping unit using methods detailed in Wieczorek (2014). In addition to the "representative" or "expected" K SAT value, SSURGO provides a "low" and "high" estimate to indicate the range of potential values for each soil component. Two additional 90-m grids of low and high $\mathrm{K}_{\mathrm{SAT}}$ values were created to facilitate an uncertainty analysis. Where SSURGO soils data were unavailable, we substituted area-weighted surface $\mathrm{K}_{\mathrm{SAT}}$ values from the State Soil Geographic (STATSGO2) general soil map of the United States (Soil Survey Staff, 2017a). Although the methods used to calculate $\mathrm{K}_{\mathrm{SAT}}$ values are identical across the SSURGO and 
STATSGO2 databases, SSURGO data are generally preferable to STATSGO2 due to the higher spatial resolution of the product (approximate minimum delineated area of 0.16 versus $6.25 \mathrm{~km}^{2}$ ). As $\mathrm{K}_{\mathrm{SAT}} \mathrm{usu}$ ally defines the lower limit of soil infiltration capacity, we assume $\mathrm{K}_{\text {SAT }}$ represents a worst-case scenario (i.e., increased likelihood of IE flow) for undisturbed soils. Figure 1 depicts the final $90 \mathrm{~m}$ representative $\mathrm{K}_{\text {SAT }}$ raster of CONUS derived from STATSGO2 filled SSURGO data.

\section{2 | Precipitation-frequency analysis}

We acquired and processed hourly precipitation records from the U.S. National Climatic Data Center for 2,421 weather stations throughout the CONUS. Only stations that possessed at least 10 years of valid precipitation data between 1980 and 2011 were included in the analysis. To insure independence between 1-hr storms, we only considered events for which there was no precipitation for at least $6 \mathrm{hr}$ before and after the precipitation event. Only the maximum value was used from periods of consecutive rainfall. We assumed that all precipitation data was rain and ignored melting snow. To account for the effects of constrained "clock hour" on observations, we adjusted hourly rainfall totals by 1.13 (Perica et al., 2013).

A frequency analysis, based on a partial duration series (PDS), was performed at each station. PDS are preferred to annual block maxima as they can better leverage the information content on extreme precipitation events from shorter meteorological records and are considered more reliable for computing frequent events (i.e., $\leq 10 \mathrm{yrs}$; Laurenson, 1987; Perica et al., 2013). The threshold for inclusion in the PDS was set equal to the 95th percentile of all 1-hr events over the period of record. This threshold minimized bias in frequency estimates while maximizing event sample size. Hourly rainfall volumes were calculated for the following average recurrence intervals (ARI; defined as the average period between years in which a given precipitation magnitude is exceeded at least once): 0.2, 0.5, 1, 5, 10, and 20 years. Empirical exceedance probabilities were computed using
Weibull plotting positions (Weibull, 1939). This non-parametric approach to estimating extreme precipitation depths is often preferred because it avoids the somewhat subjective choice of the appropriate parametric distribution (e.g., generalized extreme value, Pareto; e.g., DeGaetano, 2009), issues with parameterizing mixed distributions related to distinct atmospheric mechanisms driving rainfall extremes (e.g., Smith, Villarini, \& Baeck, 2011), and imposition of parametric distributions to ungagged areas as in NOAA Atlas 14 (Perica et al., 2013).

In order to develop maps of precipitation estimates for comparison against the soils grids, CIRF models were trained on the estimated rainfall volumes ( $R$ package party; Hothorn, Buehlmann, Dudoit, Molinaro, \& Van Der Lann, 2006, Strobl, Boulesteix, Kneib, Augustin, $\&$ Zeileis, 2008). Climatic and landscape predictor variables for each station were extracted from 30-year 4-km PRISM data (PRISM Climate Group, 2017; Table 1). Rainfall-frequency magnitudes from the nearest gaging station were used as an additional predictor. CIRF model error was assessed via out-of-bag $r$-squared values. The trained CIRF models were then used to predict rainfall volumes associated with each ARI across the CONUS at a 4-km resolution. A total of six

TABLE 1 Summary of predictor variables extracted from PRISM grids $(4 \mathrm{~km})$

\begin{tabular}{ll}
\hline PRISM predictor variable & Units \\
\hline Mean precipitation & Inches \\
\hline Mean temperature & Fahrenheit \\
\hline Minimum temperature & Fahrenheit \\
\hline Maximum temperature & Fahrenheit \\
\hline Mean dew point temperature & Fahrenheit \\
\hline Minimum vapour pressure deficit & $\mathrm{hPa}$ \\
\hline Maximum vapour pressure deficit & $\mathrm{hPa}$ \\
\hline Elevation & $\mathrm{ft}$ \\
\hline Latitude & $\mathrm{Albers}$ equal area \\
\hline Longitude & $\mathrm{Albers}$ equal area \\
\hline
\end{tabular}

Note. All climate variables correspond to 30-year normals.

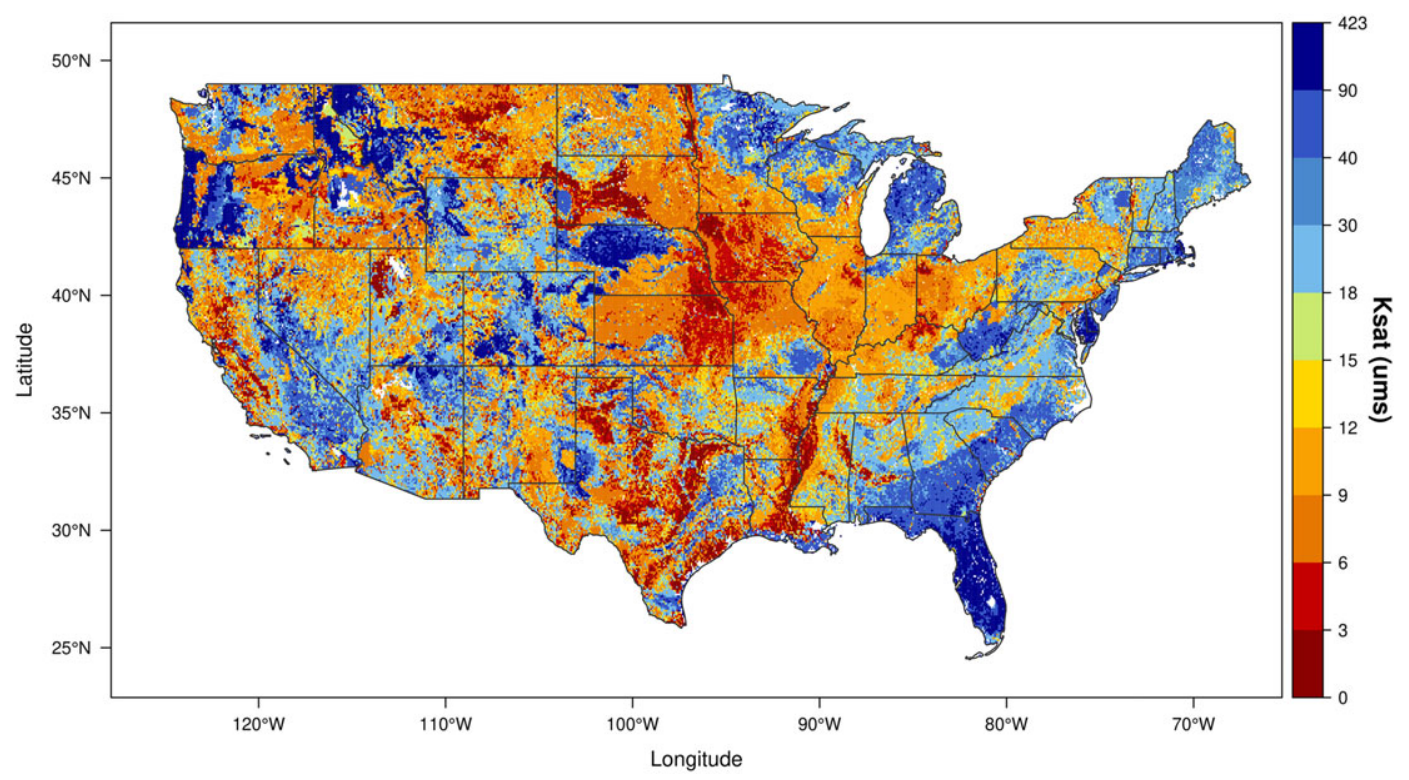

FIGURE 1 Representative saturated hydraulic conductivity values (KAT) of the surface horizon ( $\mu \mathrm{m} / \mathrm{s}$; Soil Survey Staff, 2017a, 2017b) 
weather stations were removed from the analysis due to missing or anomalous data records.

\section{3 | Determination of IE versus SE runoff}

To determine the relative potential for IE or SE runoff, we divided the rainfall-frequency grids by $\mathrm{K}_{\mathrm{SAT}}$ values extracted from the $\mathrm{K}_{\mathrm{SAT}}$ raster and multiplied by 100 . Values greater than 100 represent increasingly higher likelihoods of IE flow (as rainfall exceeds $\mathrm{K}_{\text {SAT }}$ ), whereas values less than 100 represent increasingly higher probabilities of SE flow (as $\mathrm{K}_{\mathrm{SAT}}$ exceeds rainfall). We also created a raster depicting the ARI at which $\mathrm{K}_{\mathrm{SAT}}$ was exceeded across CONUS. This analysis ignores changes in infiltration rates due to freezing soils, antecedent moisture conditions, or changes in land use. Accordingly, our results likely under-predict the prevalence of IE flow in areas with land use practices that contribute to soil compaction or during winter months when soil freezing may reduce infiltration rates (Walter et al., 2003). Likewise, we likely overestimate IE where soil properties allow much higher infiltration rates during periods of very dry antecedent conditions.

\section{3 | RESULTS}

\section{1 | Rainfall-frequency analysis}

Figure 2 illustrates the results of the CIRF model predictions for the 0.2 , $0.5,1,5,10$, and 20-year storms. Out-of-bag r-squared values ranged from 0.81 to 0.94 and were generally larger for more frequent storms.
Latitudinal and longitudinal trends are evident in the projected storm depths shown in Figure 2 and are consistent with patterns of tropical moisture export (TME) sourced extreme precipitation over the CONUS. TMEs are broadly defined by a poleward movement of warm moist air from the tropics, which precipitates over higher latitudes (Knippertz, Wernli, \& Gläser, 2013; Steinschneider \& Lall, 2016). Atlantic Ocean sourced TMEs likely drive the upper end of extreme precipitation east of 100 degrees longitude across the CONUS (Figure 2). Temperature driven rainout over the lower latitudes creates a gradient of decreasing extreme precipitation from South to North, which is confined to Central and Eastern United States due to the predominant westerly jet stream. Pacific derived TMEs similarly affect the Pacific Northwest and Southwest (Figure 2); however, they are spatially confined to the western coast due to orographic rainout over the Sierra and Rocky Mountains. The predominant westerly direction of winds across the CONUS and landforms leaves much of the Western and Central United States isolated from TME derived extreme precipitation, resulting in reduced precipitation. Further, our low meteorological station density at the regional scale could potentially under-sample local extreme precipitation event intensities.

Importantly, storm magnitudes and spatial patterns compare favourably with NOAA Atlas 14 precipitation-frequency maps (Perica et al., 2013) despite discrepancies due to differing methodologies (e.g., interpolation approaches, POT thresholds, and station filtering criteria). In general, the nearest station rainfall magnitude, mean dew point temperature, longitude, latitude, and minimum temperature were the top five most influential predictors according to unbiased variable importance scores (data not shown).

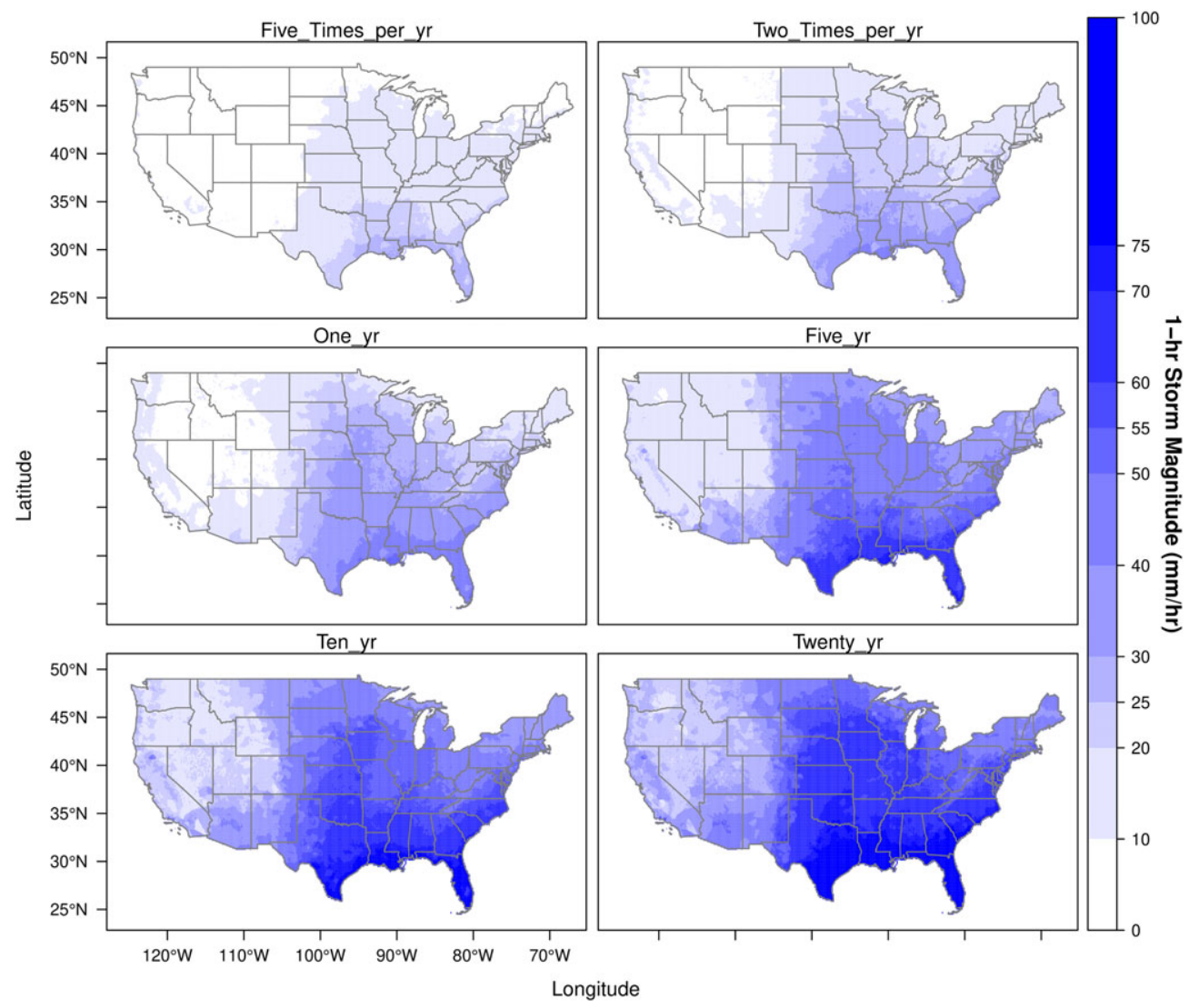

FIGURE 2 Random forest model estimates of rainfall-frequency for 0.2, 0.5, 1, 5, 10, and 20-year storms (mm/hr) 


\subsection{IE versus SE runoff}

The intensity or likelihood of IE runoff, as indicated by the degree to which 1-hr storm depths exceed representative surficial $\mathrm{K}_{\mathrm{SAT}}$, is the greatest in portions of Texas, Louisiana, Kansas, Missouri, lowa, Nebraska, and Western South Dakota (values $>100$ in Figure 3; yellow-red colour palette). SE runoff, on the other hand, is more likely in Florida, Southern Georgia, Southeastern California, and Nevada, as well as western Oregon and coastal areas of the Great Lakes region (values $<100$ in Figure 3; blue colour palette).

According to Figures 3 and 4, IE runoff is not likely to occur over much of the CONUS for 1-hr storms with an average return interval $<5$ years. Storm magnitudes $\geq 5$ years, however, are associated with IE runoff over substantial portions of the Central United States.

The distribution of IE flow is spatially consistent with patterns of TME-based extreme rainfall and low $\mathrm{K}_{\mathrm{SAT}}$. The predominance of SE flow in the Western and Central United States, despite lower $\mathrm{K}_{\mathrm{SAT}}$ values (Figure 1), is likely related to prevailing westerly winds across the CONUS, leaving much of the Western and Central United States isolated from TME derived extreme precipitation.

The prevalence of SE runoff across the Eastern United States, particularly the Southeast, is driven largely by patterns of soil texture
(Figure 1) that reduces the effects of high-intensity precipitation (Figure 2). Soil formations of the Mid- to Northern U.S. Atlantic coast are derived from a combination of sandstone and shale parent material (Soller, Reheis, Garrity, \& Van Sistine, 2009), mixed deciduous coniferous forests (McRoberts \& Tomppo, 2007), and the humid climate. The bedrock and vegetation along the Eastern United States coevolved sandy-loam and silt-loam soil formations that are more highly infiltrating. Sand-loam and sandy soils of the Southeastern United States were developed from limestone parent material (Soller et al., 2009), predominantly coniferous forests (McRoberts \& Tomppo, 2007), and a consistently wet and warm climate leading to very high infiltration capacities. Soils of low elevation land along the Atlantic coast are also influenced by deposition of highly infiltrating sandy oceanic sediments during extreme coastal weather events (Donnelly et al., 2001; Donnelly, Butler, Roll, Wengren, \& Webb, 2004).

Using SSURGO low and high $\mathrm{K}_{\mathrm{SAT}}$ estimates to create an uncertainty envelope on the prevalence of IE versus SE runoff reveals substantial variation in IE versus SE runoff on the basis of estimated soil properties (Figures $5 \&$ S4). For instance, across the six ARIs in this study, IE runoff is likely to occur over roughly $18-26 \%$ more of the CONUS when using SSURGO's low K KAT estimates (Figure S2). However, as $\mathrm{K}_{\mathrm{SAT}}$ already represents a conservative (worst-case)

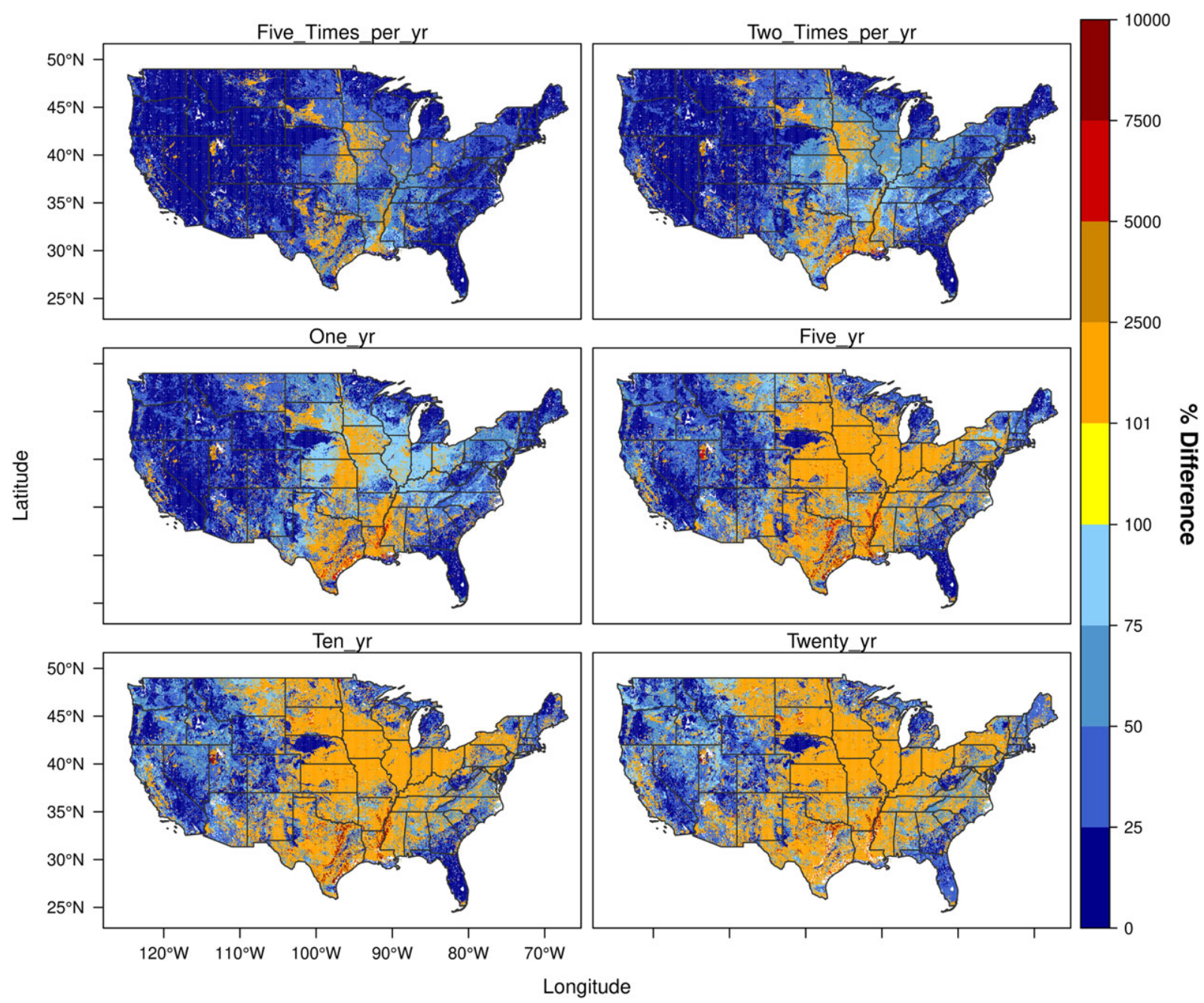

FIGURE 3 Percent difference in predicted storm magnitude and surficial $\mathrm{K}_{\mathrm{SAT}}$. Values less than 100 represent increasingly greater likelihood of saturation-excess flow, whereas values greater than 100 represent greater likelihoods of infiltration-excess flow 


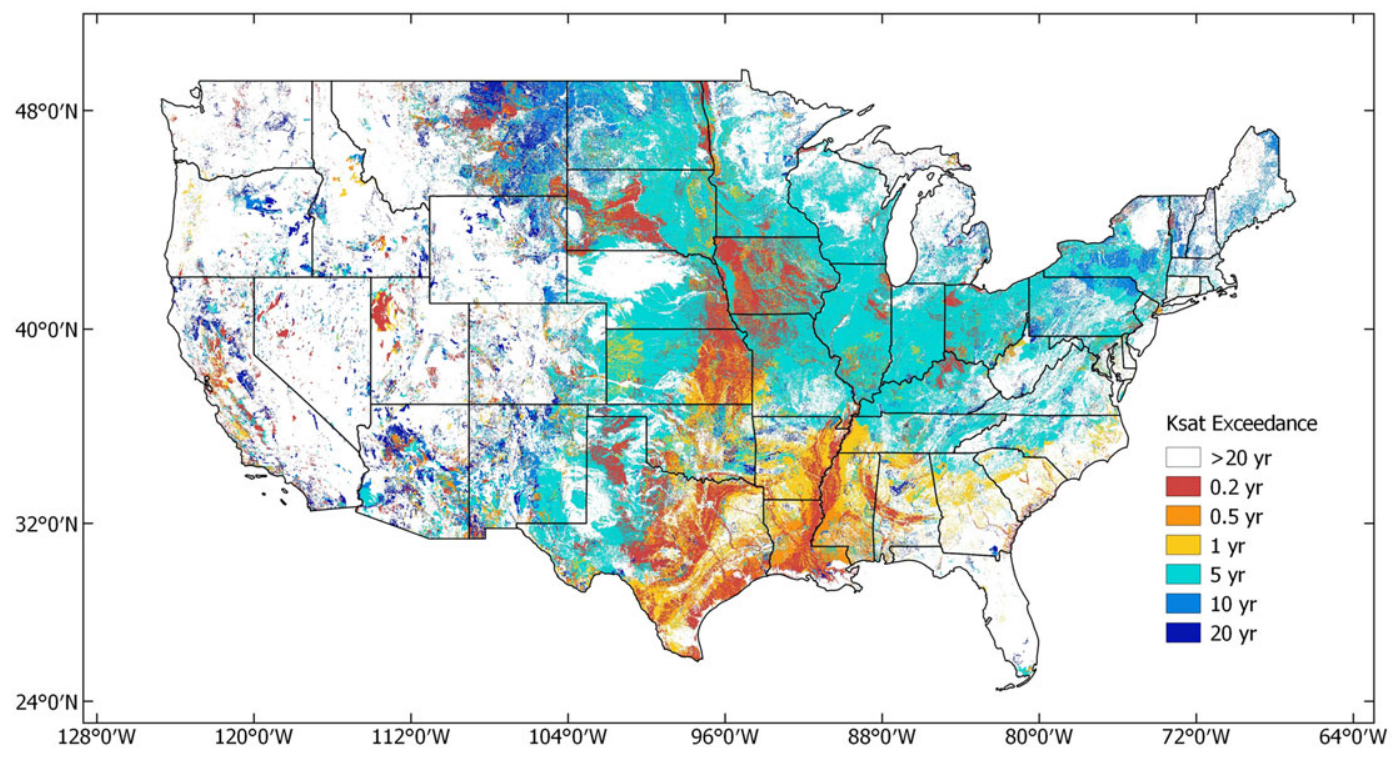

FIGURE 4 Average return interval of 1-hr storms at which $\mathrm{K}_{\mathrm{SAT}}$ is exceeded for the contiguous United States

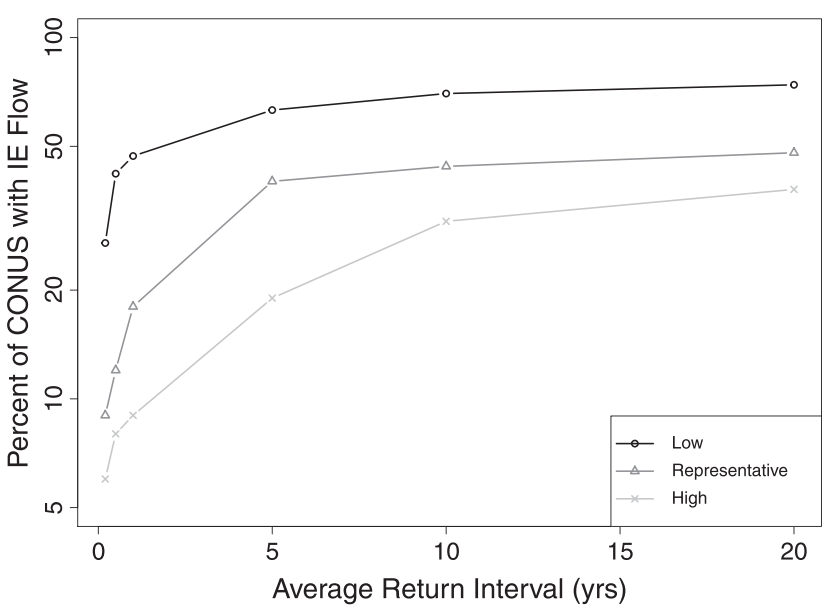

FIGURE 5 Percent of contiguous United States (CONUS) experiencing infiltration excess runoff across low, representative and high Soil Survey Geographic (SSURGO) K KAT estimates and 1-hr storm return intervals

approximation of infiltration capacity, use of SSURGO's low K KAT estimate may yield unrealistically inflated predictions of IE runoff for undisturbed soils (Figure S2). Indeed, the high SSURGO K KAT estimate may provide a better approximation of surface infiltration capacity in undisturbed soils, especially during the early stages of a storm event. Use of upper bound $\mathrm{K}_{\mathrm{SAT}}$ estimates results in a $3-10 \%$ decrease in the likelihood of IE flow across CONUS (Figure S3 \& S4).

\section{4 | DISCUSSION}

Our simple approach comparing interpolated precipitation-frequency grids with national soils data provides a first approximation of the runoff processes most likely to occur naturally throughout the CONUS. Such information can improve a host of applications by indicating whether and how topographic indices, land cover, and soils data are used in project design and planning. For example, topographic wetness indices- which are predicated on SE runoff processes-have demonstrated utility for various hydrological management questions, including predicting: (a) the spatial distribution of soil moisture (Buchanan et al., 2014; Cheng et al., 2014; Tague, Band, Kenworthy, \& Tenebaum, 2010; Tenenbaum, Band, Kenworthy, \& Tague, 2006), (b) water table depths (Easton et al., 2008), (c) denitrification zones (Anderson, Groffman, \& Walter, 2015), (d) non-point source pollution hotspots for precision agriculture (Buchanan et al., 2013), and (e) areas of high wetland potential (Horvath, Christensen, Mehaffey, \& Neale, 2017). Thus, our results can help managers and researchers better align the use of TI-derived products and inference with the regions where VSA processes predominate.

Additionally, most conventional hydrologic and water quality models and rainfall-runoff formulations are not capable of simulating coupled IE and SE runoff (e.g., NRCS curve number, Soil \& Water Assessment Tool (SWAT), Generalized Watershed Loading Function, Hydrological Simulation Program Fortran, and Hydrologic Engineering Center - Hydrologic Modeling System (HEC-HMS). This requires users to make a priori assumptions regarding the dominant runoff generating mechanism-often with little guidance. The importance of applying a valid runoff generating mechanism is underscored by the findings of numerous studies that show incorrect application of IE-based hydrologic, and water quality models in VSA dominated regions can lead to substantial errors in streamflow predictions, nutrient, and sediment transport and incorrect identification of runoff generating zones and critical source areas (Easton et al., 2008; Kan et al., 2017; Lyon, McHale, Walter, \& Steenhuis, 2006; Schneiderman et al., 2007; Valeo $\&$ Moin, 2001).

Figure 4 may also be particularly useful for water resource engineers tasked with choosing IE- or SE-based runoff formulations for engineering applications such as flood risk or culvert sizing across a variety of design storm sizes. Moreover, the reproducibility of our method provides added value as changing land use characteristics that influence infiltration rates (i.e., urbanization) and climatic changes such as intensified precipitation can be evaluated in future studies to quantify trends in runoff generating mechanisms that can impact pollution transport, flood risk, and denitrification potential. As an example, we 
used recent climate change projections of the intensification of 1-hr, 5-year rainfall (Representative Concentration Pathway 8.5) for 2040, 2070, and 2100 time horizons for New York State (DeGaetano \& Castellano, 2017) and found that the percent of New York experiencing IE flow increased by $12.4,18.4$, and 19\%, respectively (Figure S1).

\section{1 | Comparison with similar studies}

Our results are congruent with those of Walter et al. (2003), who conducted a similar analysis in SoutheasternNew York and found that IE runoff was only likely to occur for storms greater than the 3-year, 15-min event. Because our study focused on 1-hr duration storms, it is not surprising that our findings for the same region suggest IE is improbable unless the storm magnitude exceeds the larger 5-year event (Figure 4). Additionally, the spatial distribution of Wolock et al.'s (2003) TOPMODEL-based $5 \mathrm{~km}$ estimates of percent IE in total streamflow (Figure 6) compares favourably with our findings. Specifically, in both studies, IE runoff appears far more likely in the Central, Great, and Western Gulf Plain regions of the United States. Conversely, SE runoff is more probable in along Atlantic Plain, Intermountain, and large portions of the Rocky Mountains, Cascades, and Sierra Nevada mountains.

\section{2 | Uncertainty and limitations}

Continental-scale analyses require numerous assumptions that greatly simplify the natural complexity of runoff dynamics. For instance, our analysis does not account for lateral subsurface flow and preferential flow paths that can be a major component of streamflow in many regions (e.g., Pilgrim, Huff, \& Steele, 1978; Sinha, Rode, \& Borchardt, 2016). Furthermore, we acknowledge that IE and SE runoff generating mechanisms are not mutually exclusive within a given watershed or even an individual field. Complex interactions amongst, weather, climate, topography, geology, vegetation, and antecedent moisture conditions all serve to determine which mechanism may predominate at a given time or location. Even simple temporal variations in rainfall intensity that are not captured in 1-hr storm totals may lead to alternating patterns of IE and SE runoff, especially during convective storms. For instance, rainfall intensities of shorter duration periods that may occur throughout a longer 1-hr duration storm, such as 30,15 , and 5 min, are often over $50-200 \%$ greater than the 1-hour total. Consequently, using coarser temporal scales of rainfall can lead to an oversimplification of runoff generating mechanisms. Indeed, numerous researchers have found that IE and SE runoff can occur simultaneously at field, hillslope, and watershed scales (e.g., Buda, Kleinman, Srinivasan, Bryant, \& Feyereisen, 2009; Latron \& Gallart, 2008; Srinivasan, Gburek, $\&$ Hamlett, 2002). In some cases, investigators have found that dominant processes were contrary to their expectations given their knowledge of local conditions (Srinivasan, Kleinman, Sharpley, Buob, \& Gburek, 2007). It is likely that many of the contrary findings may be related to alterations in soil properties from anthropogenic land use practices that cause compaction, increased bulk density, and concomitant declines in $\mathrm{K}_{\mathrm{SAT}}$. Indeed, numerous studies conducted in diverse geologic and geographic settings have demonstrated reductions in $\mathrm{K}_{\mathrm{SAT}}$ ranging from 1.8 to 100 times due to agricultural and urban land use practices (Chen, Day, Wick, \& McGuire, 2014; Knighton, White, Lennon, \& Rajan, 2014; Singleton \& Addison, 1999; Wang, McKeague, \& SwitzerHowse, 1985). Such declines in $\mathrm{K}_{\text {SAT }}$ can have profound implications for runoff generating properties and by extension, flooding, soil erosion, and water quality. Thus, the results presented offer a broad estimate of the prevalence of SE and IE runoff. We acknowledge that locally measured infiltration rates may be most appropriate for site-specific applications of this methodology.

Antecedent soil moisture plays a direct role in partitioning gross precipitation between infiltration and surface runoff. We implemented a simplified approach to approximate infiltration rates as $\mathrm{K}_{\mathrm{SAT}}$, which provides a lower bound assuming IE conditions. Soil moisture varies spatially and temporally across CONUS with saturated conditions more prevalent in the cool season and a general decrease in

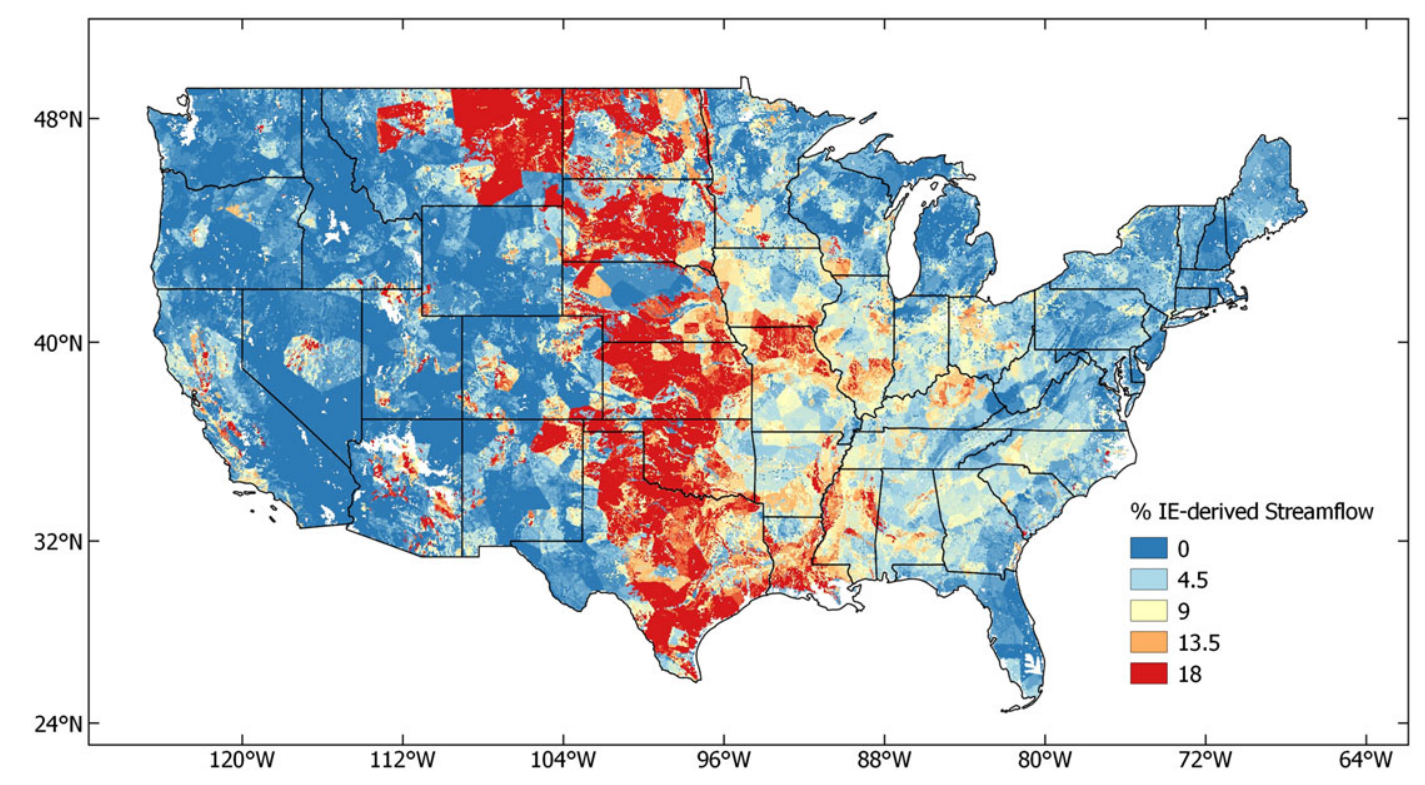

FIGURE 6 Percent of total streamflow derived from infiltration excess runoff. Adapted from Wolock (2003) 
volumetric soil water content during the summer (Pan, Cai, Chaney, Entekhabi, \& Wood, 2016) associated with increased evapotranspiration and relative to seasonal precipitation totals. Our approach neglects that instantaneous infiltration rates typically exceed $\mathrm{K}_{\mathrm{SAT}}$, leading to a general bias towards overestimating IE.

Frozen soil conditions, suppressing infiltration across higher latitude locations or elevations during the cool season, may cause overestimation of infiltration rates as $\mathrm{K}_{\mathrm{SAT}}$. As previously discussed, the timing of extreme precipitation in the Eastern United States generally occurs during the summer and late fall seasons when frozen soil conditions are unlikely reducing the significance of this simplifying assumption. Extreme precipitation along the western coast is predominantly derived via atmospheric rivers in the cold season; however, these events typically also induce a positive air temperature anomaly (Leung \& Qian, 2009). Broadly, air temperatures low enough to freeze soils will also likely cause precipitation to fall as snow, negating the runoff risk associated with extreme cool season precipitation. Our approach may underestimate the prevalence of IE occurring during transitions from cool- to warm-season that can be characterized by precipitation as rainfall occurring on frozen soils or partially-frozen soils.

Though it was beyond the scope of this research to quantitatively consider uncertainty in the estimates of extreme precipitation frequency, it is worth elaborating on the expected direction of influence of precipitation uncertainty on our results. Assuming all precipitation processes are random and time-invariant, shorter record lengths near 10 years possibly underrepresent the true variability of extreme precipitation events driven by naturally infrequent processes that generate hydrologic extremes. For example, it is well established that the upper end of extreme precipitation in the Northeast United States is dominated by TMEs (Villarini \& Smith, 2010). A point estimate of TME frequency in New York, United States with a sufficiently long meteorological record (>60 years) demonstrated an average TME frequency of 0.5 events per year, whereas locally sourced convective precipitation occurred with an average frequency of 7 events per year (Knighton, Steinschneider, \& Walter, 2017). While a 10-year observation period may capture the frequency of TME derived precipitation, the probability distribution function of rainfall magnitudes of these TME events is likely under-sampled and poorly defined.

Considering the dominant and causal atmospheric processes that induce extreme precipitation events as time-variant lends further uncertainty to this analysis. Subannual (e.g., Jones \& Carvalho, 2012; Madden-Julian Oscillation), semidecadal (e.g., Steinschneider \& Lall, 2016; El Nino Southern Oscillation), decadal, and multidecadal (e.g., Yu, Zhong, Pei, Bian, \& Heilman, 2016; North Atlantic Oscillation, Pacific Decadal Oscillation) global climate oscillations have some influence on the probability of extreme precipitation within the CONUS. Records of similar length to the period of these oscillations may over- or under-represent the periodic effect of a dynamic global climate on continental-scale precipitation extremes. Finally, we acknowledge that changes in climate forcing related to atmospheric carbon concentrations is exerting some influence on global climate patterns and in turn extreme precipitation. On average, we expect a general global increase in future precipitation extremes (Trenberth, 2011), suggesting a possible slight bias in our estimates of the prevalence of IE across the CONUS.

\section{5 | CONCLUSIONS}

Planning for resource conservation and sustainable agricultural management requires conceptually straightforward information that is well-grounded in ecohydrologic principles. Using publicly available soils and rainfall data, our analysis offers a first approximation of dominant runoff generating mechanisms across the CONUS. Results provide key insights into how climate, surficial geology, and physiography interact to produce spatial variations in key hydrologic processes at the landscape scale. Not only do our findings have implications for a suite of water quality issues (e.g., non-point source pollutant transport pathways), but also they offer critical guidance for water resource managers and environmental modellers to facilitate the identification of the most appropriate runoff formulation.

Representation of runoff modes within distributed hydrologic models and LSMs commonly relies on the assumption of homogeneity in the process driving surface runoff. Our results clearly indicate that both IE and SE runoff generation occur within the CONUS for surface runoff event frequencies as often as five times per year. This research supports the development of process-based hydrologic models for surface runoff-infiltration partitioning within the CONUS. Our methodology and results provide LSM and hydrologic model developers a reasonable framework for selecting spatially varied surface runoff generating mechanisms.

Moving forward, we envision several productive future veins of research that may broaden the impact, as well as address the limitations of this analysis. For example, $\mathrm{K}_{\mathrm{SAT}}$ estimates may be improved by incorporating land use effects (e.g., adjusting $\mathrm{K}_{\mathrm{SAT}}$ values to account for impervious surface) and by utilizing POLARIS soils data (Chaney et al., 2016), which addresses several well-known shortcomings of the SSURGO database (e.g., large data gaps and artificial discontinuities at political boundaries). Additionally, the geographic and temporal scope of this study could be expanded by using Climate Forecast System Reanalysis climate data to conduct global-scale rainfall-frequency analyses, and global climate model outputs could be used to project how future changes in rainfall intensities may affect spatio-temporal predominance of IE versus SE runoff. Finally, useful insights into the hydrologic implications of predominant runoff generating mechanisms may be afforded by linking spatial patterns of IE and SE flow with hydrologic response at the watershed outlet via evaluation of flow statistics at corresponding United States Geological Survey gages.

\section{ORCID}

Brian Buchanan (D) http://orcid.org/0000-0003-0641-4450

Daniel A. Auerbach (1) http://orcid.org/0000-0002-3655-5206

\section{REFERENCES}

Anderson, T., Groffman, P. M., \& Walter, M. T. (2015). Using a soil topographic index to distribute denitrification fluxes across a northeastern headwater catchment. Journal of Hydrology, 522, 123-134. https:// doi.org/10.1016/j.jhydrol.2014.12.043

Beven, K., \& Binley, A. (1992). The future of distributed models: Model calibration and uncertainty prediction. Hydrological Processes, 6, 279-298. https://doi.org/10.1002/hyp.3360060305 
Beven, K., Cloke, H., Pappenberger, F., Lamb, R., \& Hunter, N. (2015) Hyperresolution information and hyperresolution ignorance in modelling the hydrology of the land surface. Science China Earth Sciences, 58(1), 25-35. https://doi.org/10.1007/s11430-014-5003-4

Beven, K. J., \& Kirkby, M. J. (1979). A physically based, variable contributing area model of basin hydrology. Hydrological Sciences Bulletin, 24, 43-69. https://doi.org/10.1080/02626667909491834

Buchanan, B. P., Archibald, J. A., Easton, Z. M., Shaw, S. B., Schneider, R. L., \& Walter, M. T. (2013). A phosphorus index that combines critical source areas and transport pathways using a travel time approach Journal of Hydrology, 486, 123-135. https://doi.org/10.1016/j. jhydrol.2013.01.018

Buchanan, B. P., Flemming, M., Schneider, R. L., Richards, B. K., Archibald, J., Qiu, Z., \& Walter, M. T. (2014). Evaluating topographic wetness indices across central New York agricultural landscapes. Hydrology and Earth System Sciences, 18, 3279-3299. https://doi.org/10.5194/ hess-18-3279-2014

Buda, A. R., Kleinman, P. J. A., Srinivasan, M. S., Bryant, R. B., \& Feyereisen, G. W. (2009). Factors influencing surface runoff generation from two agricultural hillslopes in central Pennsylvania. Hydrological Processes, 23(9), 1295-1312. https://doi.org/10.1002/hyp.7237

Chaney, N. W., Wood, E. F., McBratney, A. B., Hempel, J. W., Nauman, T. W., Brungard, C. W., et al. (2016). POLARIS: A 30-meter probabilistic soil series map of the contiguous United States. Geoderma, 274, 54-67. https://doi.org/10.1016/j.geoderma.2016.03.025

Chang, H., Johnson, G., Hinkley, T., \& Jung, L. (2014). Spatial analysis of annual runoff ratios and their variability across the contiguous U.S. Journal of Hydrology, 511, 387-402. https://doi.org/10.1016/j. jhydrol.2014.01.066

Chen, Y., Day, S. D., Wick, A. F., \& McGuire, K. J. (2014). Influence of urban land development and subsequent soil rehabilitation on soil aggregates, carbon, and hydraulic conductivity. Science of the Total Environment, 494-495, 329-336.

Cheng X, Dahlke HS, Shaw S, Marjerison R, Yearick C, Walter MT. 2014 Improving risk estimates of runoff producing areas: Formulating variable source areas as a bivariate process. Journal of Environmental Management 137: 146-156. doi.org/10.1016/j.jenvman.2014.02.006.

DeGaetano, A. T. (2009). Time-dependent changes in extremeprecipitation return-period amounts in the continental United States. Journal of Applied Meteorology and Climatology, 48, 2086-2099. https://doi.org/10.1175/2009JAMC2179.1

DeGaetano, A. T., \& Castellano, C. M. (2017). Future projections of extreme precipitation intensity-duration-frequency curves for climate adaptation planning in New York State. Climate Services, 5, 23-25. https://doi.org/10.1016/j.cliser.2017.03.003

Donnelly, J. P., Bryant, S. S., Butler, J., Dowling, J., Fan, L., Hausmann, N., \& Webb, T. (2001). $700 \mathrm{yr}$ sedimentary record of intense hurricane landfalls in southern New England. GSA Bulletin, 113(6), 714-727. https:// doi.org/10.1130/0016-7606(2001)113<0714:YSROIH >2.0.CO;2

Donnelly, J. P., Butler, J., Roll, S., Wengren, M., \& Webb, T. (2004). A backbarrier overwash record of intense storms from Brigantine, New Jersey. Marine Geology, 210(1-4), 107-121. https://doi.org/10.1016/ j.margeo.2004.05.005

Dunne, T., \& Leopold, L. B. (1978). In W. H. Freeman (Ed.), Water in environmental planning. New York, New York.

Easton, Z. M., Fuka, D. R., Walter, M. T., Cowan, D. M., Schneiderman, E. M., \& Steenhuis, T. S. (2008). Re-conceptualizing the soil and water assessment tool (SWAT) model to predict runoff from variable source areas. Journal of Hydrology, 348, 279-291. https://doi.org/10.1016/j. jhydrol.2007.10.008

Easton, Z. M., Walter, M. T., Zion, M., Schneiderman, E. M., \& Steenhuis, T. S. (2009). Integrating source specific chemistry in basin scale models to predict phosphorus export from agricultural watersheds. Journal Environmental Engineering ASCE, 135(1), 25-35. https://doi.org/10.1061/ (ASCE)0733-9372(2009)135:1(25)
Falcone, J. A., Carlisle, D. M., Wolock, D. M., \& Meador, M. R. (2010). GAGES II: A stream gage database for evaluating natural and altered flow conditions in the conterminous United States. Ecology, 91, 621. https://doi.org/10.1890/09-0889.1

Freund, E. R., Fan, Y., \& Kirchner, J. W. (2017). Averaging over spatial heterogeneity leads to overestimation of ET in large scale Earth system models. Geophysical Research Abstracts, 19.

Horton, R. E. (1933). The role of infiltration in the hydrologic cycle. Transactions American Geophysical Union, 14, 446-460. https://doi.org/ 10.1029/TR014i001p00446

Horton, R. E. (1940). An approach toward a physical interpretation of infiltration capacity. Soil Science Society of America Proceedings, 6, 399-417.

Horvath, E. K., Christensen, J. R., Mehaffey, M. H., \& Neale, A. C. (2017). Building a potential wetland restoration indicator for the contiguous United States. Ecological Indicators, 83, 463-473. https://doi.org/ 10.1016/j.ecolind.2017.07.026

Hothorn, T., Buehlmann, P., Dudoit, S., Molinaro, A., \& Van Der Lann, M. (2006). Survival ensembles. Biostatistics, 7, 355-373. https://doi.org/ 10.1093/biostatistics/kxj011

Jones, C., \& Carvalho, L. M. (2012). Spatial-intensity variations in extreme precipitation in the contiguous United States and the Madden-Julian oscillation. Journal of Climate, 25(14), 4898-4913. https://doi.org/ 10.1175/JCLI-D-11-00278.1

Kan, G., He, X., Ding, L., Li, J., Liang, K., \& Hong, Y. (2017). Study on applicability of conceptual hydrological models for flood forecasting in humid, semi-humid semi-arid and arid basins in China. Water, 9(10), 719. https://doi.org/10.3390/w9100719

Kirchner, J. W. 2006. Getting the right answers for the right reasons: Linking measurements, analyses, and models to advance the science of hydrology, Water Resources Research, 42, W03S04, https://doi.org/ 10.1029/2005WR004362.

Knight, R. R., Gain, W. S., \& Wolfe, W. J. (2011). Modelling ecological flow regime: An example from the Tennessee and Cumberland River Basins. Ecohydrology, 5, 613-627. https://doi.org/10.1002/eco.246

Knighton, J., Steinschneider, S., \& Walter, M. T. (2017). A vulnerabilitybased, bottom-up assessment of future riverine flood risk using a modified peaks-over-threshold approach and a physically based hydrologic model. Water Resources Research, 53, 10043-10064. https://doi.org/ 10.1002/2017WR021036

Knighton, J., White, E., Lennon, E., \& Rajan, R. (2014). Development of probability distributions for urban hydrologic model parameters and a Monte Carlo analysis of model sensitivity. Hydrological Processes, 28(19), 5131-5139. https://doi.org/10.1002/hyp.10009

Knippertz, P., Wernli, H., \& Gläser, G. (2013). A global climatology of tropical moisture exports. Journal of Climate, 26, 3031-3045. https:// doi.org/10.1175/JCLI-D-12-00401.1

Latron, J., \& Gallart, F. (2008). Runoff generation processes in a small Mediterranean research catchment (Vallcebre, Eastern Pyrenees). Journal of Hydrology, 358(3-4), 206-220. https://doi.org/10.1016/j. jhydrol.2008.06.014

Laurenson, E. M. (1987). Back to basics on flood frequency analysis. Civil engineers transactions, institution of engineers, Australia, CE29: 47-53.

Leung, L. R., \& Qian, Y. (2009). Atmospheric rivers induced heavy precipitation and flooding in the western US simulated by the WRF regional climate model. Geophysical Research Letters, 36(3). https://doi.org/ 10.1029/2008GL036445

Lyon, S. W., McHale, M. R., Walter, M. T., \& Steenhuis, T. S. (2006). The impact of runoff generation mechanisms on the location of critical source areas. JAWRA Journal of the American Water Resources Association, 42, 793-804. https://doi.org/10.1111/j.1752-1688.2006. tb04493.x

McRoberts, R. E., \& Tomppo, E. O. (2007). Remote sensing support for national forest inventories. Remote Sensing of Environment, 110(4), 412-419. https://doi.org/10.1016/j.rse.2006.09.034 
Mendoza, P. A., Clark, M. P., Barlage, M., Rajagopalan, B., Samaniego, L., Abramowitz, G., \& Gupta, H. (2015). Are we unnecessarily constraining the agility of complex process-based models? Water Resources Research, 51(1), 716-728. https://doi.org/10.1002/2014WR015820

Nijzink, R. C., \& Savenije, H. H. (2016). The importance of topographycontrolled sub-grid process heterogeneity and semi-quantitative prior constraints in distributed hydrological models. Hydrology and Earth System Sciences, 20(3), 1151-1176. https://doi.org/10.5194/hess-201151-2016

Pan, M., Cai, X., Chaney, N. W., Entekhabi, D., \& Wood, E. F. (2016). An initial assessment of SMAP soil moisture retrievals using high-resolution model simulations and in situ observations. Geophysical Research Letters, 43(18), 9662-9668. https://doi.org/10.1002/2016GL069964

Perica, S., Martin, D., Pavlovic, S., Roy, I., St. Laurent, M., Trypaluk, C., ... Bonnin, G. (2013). NOAA Atlas 14 volume 9 version 2, precipitationfrequency atlas of the United States, Southeastern States. Silver Spring, MD: NOAA, National Weather Service.

Pilgrim, D. H., Huff, D. D., \& Steele, T. D. (1978). A field evaluation of subsurface and surface runoff: II. Runoff Processes. Journal of Hydrology, 38(3-4), 319-341. https://doi.org/10.1016/0022-1694(78)90077-X

PRISM Climate Group 2017, Oregon State University, http://prism. oregonstate.edu/normals/; created 4 Feb 2004.

Schneiderman, E. M., Steenhuis, T. S., Thongs, D. J., Easton, Z. M., Zion, M. S., Mendoza, G. F., ... Neal, A. L. (2007). Incorporating variable source area hydrology into the curve number based generalized watershed loading function model. Hydrological Processes, 21, 3420-3430. https://doi.org/10.1002/hyp6556.

Segura, C., Caldwell, P., Sun, G., McNulty, S., \& Zhang, Y. (2014). A model to predict stream water temperature across the conterminous USA. Hydrological Processes, 29, 2178-2195. https://doi.org/10.1002/hyp.10357

Shrestha, P., Sulis, M., Simmer, C., \& Kollet, S. (2015). Impacts of grid resolution on surface energy fluxes simulated with an integrated surfacegroundwater flow model. Hydrology and Earth System Sciences, 19(10), 4317-4326. https://doi.org/10.5194/hess-19-4317-2015

Shrestha, P., Sulis, M., Simmer, C., \& Kollet, S. (2018). Effects of horizontal grid resolution on evapotranspiration partitioning using TerrSysMP. Journal of Hydrology, 557, 910-915. https://doi.org/10.1016/j. jhydrol.2018.01.024

Singleton, P. L., \& Addison, B. (1999). Effects of cattle treading on physical properties of three soils used for dairy farming in the Waikato, North Island, New Zealand. Soil Research, 37, 891-902.

Sinha, S., Rode, M., \& Borchardt, D. (2016). Examining runoff generation processes in the Selke catchment in central Germany: Insights from data and semi-distributed numerical model. Journal of Hydrology, 7, 38-54.

Smith, J. A., Villarini, G., \& Baeck, M. L. (2011). Mixture distributions and the hydroclimatology of extreme rainfall and flooding in the eastern United States. Journal of Hydrometeorology, 12(2), 294-309. https:// doi.org/10.1175/2010JHM1242.1

Soil Survey Staff. (2017a). Natural Resources Conservation Service, United States Department of Agriculture. Web Soil Survey. Available online at http://websoilsurvey.nrcs.usda.gov/. Accessed February 10, 2017.

Soil Survey Staff. (2017b). Natural Resources Conservation Service, United States Department of Agriculture. Soil Survey Geographic (SSURGO) Database for USA. Available online. Accessed February 10, 2017.

Soller, D. R., Reheis, M. C., Garrity, C. P., \& Van Sistine, D. R. (2009). Map database for surficial materials in the conterminous United States: $U$. S. Geological Survey Data Series 425, scale 1:5,000,000 [https:// pubs.usgs.gov/ds/425/]

Srinivasan, M. S., Gburek, W. J., \& Hamlett, J. M. (2002). Dynamics of stormflow generation-A hillslope-scale field study in east-central Pennsylvania, USA. Hydrological Processes, 16(3), 649-665. https:// doi.org/10.1002/hyp.311

Srinivasan, M. S., Kleinman, P. J. A., Sharpley, A. N., Buob, T., \& Gburek, W. J. (2007). Hydrology of small field plots used to study phosphorus runoff under simulated rainfall. Journal of Environmental Quality, 36, 1833-1842. https://doi.org/10.2134/jeq2007.0017
Steinschneider, S., \& Lall, U. (2016). El Niño and the US precipitation and floods: What was expected for the January-March 2016 winter hydroclimate that is now unfolding? Water Resources Research, 52(2), 1498-1501. https://doi.org/10.1002/2015WR018470

Strobl, C., Boulesteix, A., Kneib, T., Augustin, T., \& Zeileis, A. (2008). Conditional variable importance for random forests. BMC Bioinformatics, 9, 307. https://doi.org/10.1186/1471-2105-9-307

Tague, C., Band, L., Kenworthy, S., \& Tenebaum, D. (2010). Plot- and watershed-scale soil moisture variability in a humid Piedmont watershed. Water Resources Research, 46, W12541. https://doi.org/ 10.1029/2009WR008078

Tenenbaum, D. E., Band, L. E., Kenworthy, S. T., \& Tague, C. L. (2006). Analysis of soil moisture patterns in forested and suburban catchments in Baltimore, Maryland, using high-resolution photogrammetric and LIDAR digital elevation datasets. Hydrological Processes, 20, 219-240. https://doi.org/10.1002/hyp.5895

Tesfa, T. K., Ruby Leung, L., Huang, M., Li, H. Y., Voisin, N., \& Wigmosta, M. S. (2014). Scalability of grid-and subbasin-based land surface modeling approaches for hydrologic simulations. Journal of Geophysical Research: Atmospheres, 119(6), 3166-3184. https://doi.org/ 10.1002/2013JD020493

Trenberth, K. E. (2011). Changes in precipitation with climate change. Climate Research, 47, 123-138. https://doi.org/10.3354/cr00953

Valeo, C., \& Moin, S. M. A. (2001). Hortonian and Variable Source Area Modeling in Urbanizing Basins. Journal of Hydrologic Engineering, 6(4), 328-335. https://doi.org/10.1061/(ASCE)1084-0699(2001)6:4(328)

Villarini, G., \& Smith, J. A. (2010). Flood peak distributions for the eastern United States. Water Resources Research, 46(6). https://doi.org/ 10.1029/2009WR008395

Walter, M. T., Mehta, V. K., Marrone, A. M., Boll, J., Gérard-Merchant, P., Steenhuis, T. S., \& Walter, M. F. (2003). A simple estimation of the prevalence of Hortonian flow in New York City's watersheds. ASCE Journal of Hydrologic Engineering, 8, 214-218. https://doi.org/ 10.1061/(ASCE)1084-0699(2003)8:4(214)

Wang, C., McKeague, J. A., \& Switzer-Howse, K. D. (1985). Saturated hydraulic conductivity as an indicator of structural degradation in clayey soils of Ottawa area, Canada. Soil and Tillage Research, 5(1), 19-31. https://doi.org/10.1016/S0167-1987(85)80014-3

Weibull, W. (1939). A statistical theory of strength of materials. Ing. Vetensk. Akad. Handl, 151, 1-45.

Wieczorek, M. E. (2014). Area- and depth-weighted averages of selected SSURGO variables for the conterminous United States and District of Columbia. URL: https://water.usgs.gov/lookup/getspatial?ds866_ ssurgo_variables. Accessed January 15, 2017.

Wolock, D. M. (2003). Infiltration-excess overland flow estimated by TOPMODEL for the conterminous United States. US Geological Survey Open-File Report 03-310, digital data set. Last assessed on June 18, 2017 at http://ks.water.usgs.gov/pubs/abstracts/of.03-310.htm

Yu, L., Zhong, S., Pei, L., Bian, X., \& Heilman, W. E. (2016). Contribution of large-scale circulation anomalies to changes in extreme precipitation frequency in the United States. Environmental Research Letters, 11(4), 044003. https://doi.org/10.1088/1748-9326/11/4/044003

\section{SUPPORTING INFORMATION}

Additional supporting information may be found online in the Supporting Information section at the end of the article.

How to cite this article: Buchanan B, Auerbach DA, Knighton J, et al. Estimating dominant runoff modes across the conterminous United States. Hydrological Processes. 2018;32: 3881-3890. https://doi.org/10.1002/hyp.13296 